\title{
NON-SEROTONERGIC ORIGINS OF THE DORSOLATERAL FUNICULUS IN THE RAT VENTRAL MEDULLA ${ }^{1}$
}

\author{
JAN N. JOHANNESSEN, ${ }^{2}$ LINDA R. WATKINS, AND DAVID J. MAYER \\ Department of Physiology and Biophysics, Medical College of Virginia, Richmond, Virginia 23298
}

Received June 13, 1983; Revised August 29, 1983; Accepted October 13, 1983

\begin{abstract}
Cells within the ventral medulla whose axons descend to the spinal dorsal horn via the dorsolateral funiculus (DLF) play an important role in pain modulation. Previous evidence suggests that this pathway is primarily serotonergic. We have examined this hypothesis directly using combined retrograde horseradish peroxidase/serotonin immunohistochemical staining. Cells of the ventral medulla contributing to the DLF were found to be largely non-serotonergic. This result was confirmed by two approaches: by the absence of a significant number of double-labeled cells following discrete horseradish peroxidase labeling of the DLF and by the persistence of double-labeled cells in animals with DLF lesions made rostral to intraspinal injections of horseradish peroxidase solutions. The conclusion is made that the previously described nucleus raphe magnus-DLF-dorsal horn pathway is predominantly non-serotonergic.
\end{abstract}

The integrity of descending axons within the spinal dorsolateral funiculus (DLF) has proved essential for the expression of analgesia elicited by a variety of methods. It is widely accepted that the specific population of DLF fibers critical for analgesia is derived from serotonergic neurons located in the ventromedial medulla. In theory, activation of this serotonergic bulbospinal pathway inhibits neural input from tissue-damaging stimuli at the spinal level. Support for this model stems from two lines of evidence. The first suggests that analgesia is attenuated by pharmacologic interference with spinal serotonin $(5-\mathrm{HT})$ function, while analgesia results from and is accompanied by increases in spinal 5-HT activity. The second provides clear evidence that the DLF is critical for analgesia, while suggesting that the origins of the DLF in the ventral medulla (an area involved in the mediation of antinociception) are largely serotonergic.

Accumulating behavioral, biochemical, electrophysiological, and anatomical results provide circumstantial evidence that bulbospinal 5 -HT pathways mediate analgesia. Behavioral evidence indicating a physiological role for descending 5-HT pathways in mediating morphine analgesia was first provided by Vogt (1973). Selective spinal 5-HT depletion slightly diminished the anal-

\footnotetext{
1 This work was supported by United States Public Health Service Grant DA 00576 to D. J. M. We wish to thank Dr. Robert Elde for the serotonin antiserum, and Ingrid Kinscheck and Holly Shumaker for technical assistance.

${ }^{2}$ To whom correspondence should be sent, at his present address: Laboratory of Clinical Science, Building 10, Room 3N-322, NIMH, Bethesda, MD 20205.
}

gesic responses of rats to low systemic doses of morphine. Subsequently, intrathecal injections of putative $5-\mathrm{HT}$ receptor blockers have been shown to attenuate analgesia elicited by morphine injected into the periaqueductal gray (PAG) (Yaksh, 1979). Conversely, intrathecal injections of high doses of 5-HT cause an increase in tail flick latency (Wang, 1977). Biochemical data correlate with the behavioral results: increases in spinal 5-HT turnover are observed in response to systemic opiates and electrical stimulation of the ventromedial medulla (Shiomi et al., 1978; Bourgoin et al., 1980)-manipulations which result in analgesia. Engberg et al. (1968) provided the first electrophysiological evidence for an inhibitory serotonergic pathway from the medulla to the spinal cord. They observed a slight attenuation of the tonic inhibition exerted by the medulla on spinal cord cells following the systemic administration of putative 5 -HT receptor blockers. Subsequently, iontophoretic applications of 5-HT to sensory neurons in the spinal cord have been shown to depress their responses to noxious peripheral stimuli (Randic and Yu, 1976; Belcher et al., 1978; Headley et al., 1978; Jordan et al., 1978). However, depression of tonic firing rates may also result from 5-HT applications (Belcher et al., 1978). Finally, anatomical studies have identified an extensive network of 5-HT terminals in the dorsal horn (Ruda and Gobel, 1980), an area which participates in the modulation of ascending sensory information.

There is convincing evidence that both analgesia and the electrophysiological sequelae resulting from manipulations which produce analgesia require the integrity of the DLF. Behavioral experiments have shown that le- 
sions of the DLF will block analgesia induced by electrical stimulation of the PAG (Basbaum et al., 1977), systemic morphine (Basbaum et al., 1977; Rydenhag and Andersson, 1981), microinjection of morphine into the PAG (Murfin et al., 1976), and various environmental manipulations (Watkins and Mayer, 1982). Electrophysiological studies have demonstrated the essential role of the DLF in maintaining the tonic inhibition of flexion reflexes seen in the decerebrate state (Holmqvist and Lundberg, 1959). This inhibition is mimicked by direct electrical stimulation of the DLF (Holmqvist and Lundberg, 1959). The attenuation of dorsal horn cells' responses to noxious stimuli resulting from stimulation of the ventromedial medulla is also dependent on the DLF (Fields et al., 1977; Willis et al., 1977). Identification of the supraspinal origins of the DLF has revealed a large contribution from cells of the ventral medulla (Basbaum and Fields, 1979; Watkins et al., 1980), specifically nucleus raphe magnus and the ventral portions of the nucleus reticularis gigantocellularis: areas from which analgesia can be elicited by electrical or chemical stimulation (Akaike et al., 1978; Dickenson et al., 1979; Oliveras et al., 1975; Satoh et al., 1980). The proximity of these cells to the serotonergic cell group B3 has led to the proposal that these medullary cells at the origin of the DLF are serotonergic (Watkins et al., 1980). A pathway originating in the nucleus raphe magnus, descending via the DLF, and terminating in the spinal dorsal horn has been described (Basbaum et al., 1976).

Recently, however, the use of direct applications of monoaminergic neurotoxins to the spinal cord has demonstrated that spinal 5-HT is not necessary for analgesia produced by some methods. Analgesia produced by stimulation of, or morphine microinjection into, the PAG (Johannessen et al., 1982) or by systemic morphine (Proudfit and Yaksh, 1980) is unaffected by spinal 5-HT depletion. Furthermore, the original study of Vogt (1973), often cited as evidence for the serotonergic mediation of descending inhibition, reported the effects of spinal 5HT depletion on morphine analgesia to be "mild" as compared to a manipulation which depleted both spinal and medullary 5-HT. Electrophysiological evidence indicates that the inhibition of spinal nociceptive responses by medullary stimulation is, at best, minimally affected by 5 -HT blockers (Griersmith et al., 1981; Yezierski et al., 1982). Recent studies have found the tonic descending inhibition of dorsal horn cells to be completely unaffected by the administration of a 5-HT synthesis inhibitor (Soja and Sinclair, 1980) or by putative 5-HT antagonists (Griersmith et al., 1981). There are, then, lines of direct evidence which indicate that spinal 5-HT is not necessary for the production of analgesia.

In light of the functional significance currently placed on inhibitory bulbospinal 5-HT pathways within the DLF, we thought it important to examine whether the medullary cells which descend via the DLF are, in fact, serotonergic. The recently reported double labeling technique (Bowker et al., 1981b), which allows simultaneous visualization of retrogradely transported horseradish peroxidase (HRP) and serotonin-like immunoreactivity (SLI), has enabled us to address this question directly.

Retrograde labeling from the cervical DLF was chosen for several reasons. First, the pattern of medullary cells retrogradely labeled from various spinal levels remains constant, but the number of cells labeled from cervical implants is greater (Watkins et al., 1980), maximizing the chances of seeing double-labeled cells. Second, Rydenhag and Andersson (1981) have shown that all DLF lesions made above spinal segment T9 are effective in blocking morphine analgesia. Thus the descending inhibitory pathways activated by morphine remain within the DLF until T9. Finally, the question being addressed has as much functional relevance as anatomical relevance. As such, the fact that cervical DLF lesions are effective in blocking analgesia induced by a variety of methods (Rydenhag and Andersson, 1981; Watkins and Mayer, 1982 ) is sufficient justification for restricting the HRP implants to the cervical level.

\section{Materials and Methods}

Experimental design. Two approaches were used to test whether the medullary origins of the DLF in the rat are serotonergic. In most cases, unilateral retrograde labeling with HRP from one cervical DLF (C4-5) was combined with 5-HT immunohistochemistry. To confirm the efficacy of the double labeling technique, double staining was carried out after large HRP injections into the cord. Additionally, double labeling of 5-HT cells was attempted using large spinal HRP injections in animals in which one or both DLFs were cut rostral to the injection site.

Retrograde Labeling. Discrete retrograde labeling from the DLF was accomplished by the method of Griffin et al. (1979). Solid HRP was incorporated into $0.2 \mathrm{ml}$ of a $15 \%$ polyacrylamide gel (Bio-Rad). A minute piece of HRP gel was cut, allowed to dry, and surgically implanted into a small unilateral incision of the cervical DLF (C45). To achieve more diffuse retrograde labeling from the cord, a $20 \%$ (w/v in saline) liquid HRP solution was used. Multiple injections totaling $10 \mu \mathrm{l}$ were made through a 33 gauge needle over a 1-cm segment of lumbar cord. All results, unless otherwise noted, represent a 2 day survival after HRP administration.

Histological procedures. Rats were treated with $25 \mathrm{mg} /$ $\mathrm{kg}$ of Nembutal (sodium pentobarbital) given subcutaneously, $100 \mathrm{mg} / \mathrm{kg}$ of L-tryptophan (Sigma) dissolved in saline and injected intraperitoneally, and $50 \mathrm{mg} / \mathrm{kg}$ of pargyline hydrochloride (Sigma) injected intraperitoneally. Two hours later animals were dosed with barbiturate $(70 \mathrm{mg} / \mathrm{kg}$ ) and perfused transcardially with 500 $\mathrm{ml}$ of heparinized saline followed by $500 \mathrm{ml}$ of cold paraformaldehyde (3.5 to $4 \%$ ) in phosphate-buffered saline (PBS), pH 7.4. The brains and spinal cords were immediately removed and placed in cold $10 \%$ sucrose in PBS, where they remained overnight until sectioning.

Double retrograde/5-HT staining was carried out according to the method of Bowker et al. (1981a). Frozen sections $(30 \mu \mathrm{m})$ of the medulla were collected in cold PBS. For retrograde staining, free floating sections were incubated at room temperature through the following series of solutions: $0.1 \mathrm{M}$ Tris buffer, $\mathrm{pH} 7.4,10 \mathrm{~min}$; $0.5 \% \mathrm{CoCl}_{2}$ in $0.1 \mathrm{~m}$ Tris, $\mathrm{pH} 7.4,10 \mathrm{~min} ; 0.1 \mathrm{M}$ Tris, $\mathrm{pH}$ 7.4, $10 \mathrm{~min}$; PBS, pH 7.4, $10 \mathrm{~min}$; and 3,3'-diaminobenzidine hydrochloride (DAB, Sigma), $25 \mathrm{mg} / 100 \mathrm{ml}$ in PBS, pH 7.6, 10 min. A solution of $\mathrm{H}_{2} \mathrm{O}_{2}(0.5 \mathrm{ml}$ of $3 \%$ $\mathrm{H}_{2} \mathrm{O}_{2} / 100 \mathrm{ml}$ ) was added to the DAB solution and incu- 
bation was continued for an additional $15 \mathrm{~min}$. Two final washes in PBS preceded the 5-HT staining. Sections of the spinal HRP-gel implant site were collected into PBS, then reacted with benzidine dihydrochloride (BDHC) (Mesulam, 1976).

To visualize the SLI cells, free floating sections were incubated in refrigerated antiserum to 5 -HT (donated by Dr. Robert Elde). Dilutions ranging from 1:2000 to 1:4000 were made in PBS ( $\mathrm{pH} 7.4$ ) containing $1 \%$ normal goat serum (Antibodies, Inc.). After 2 days, sections were washed overnight in cold PBS. Subsequent incubations, all at room temperature, were as follows: goat anti-rabbit IgG (Antibodies, Inc.) 1:150 in PBS, $3 \mathrm{hr}$; PBS wash twice for $1 \mathrm{hr}$; and rabbit peroxidase-antiperoxidase (Sternberger-Meyer) 1:80, $3 \mathrm{hr}$; PBS wash twice for $1 \mathrm{hr}$. 'The peroxidase was reacted in a solution of DAB (15 $\mathrm{mg} / 100 \mathrm{ml}$ in Tris, $\mathrm{pH} 7.5$, containing $0.5 \mathrm{ml}$ of $3 \%$ $\mathrm{H}_{2} \mathrm{O}_{2}$ ). The optimum incubation time was determined empirically for each tissue batch by reacting a few sections for times ranging from 2 to $20 \mathrm{~min}$ and immediately mounting and viewing these sections before developing the remaining sections. The tissue was then washed in PBS and mounted from $1.5 \%$ alcoholic gelatin onto slides. After air drying, the sections were dehydrated through a graded series of alcohols, cleared in xylene and coverslipped.

In some cases, alternate medullary sections were developed for retrograde HRP only using $\mathrm{BDHC}$, so that the efficacy of the DAB-CoCl ${ }_{2}$ retrograde staining could be monitored. The distribution of retrogradely labeled cells visualized by the two methods could thus be compared.

\section{Results}

Cells in the ventral medulla which labeled from the cervical DLF were found to be almost exclusively nonserotonergic. At the level which includes the facial nucleus and nucleus raphe magnus no more than two double-labeled cells were ever seen in a single section. Unilateral retrograde labeling from the DLF combined with 5-HT immunohistochemistry produced the staining pattern seen in Figure 1A. Laterally, cells giving rise to the DLF lie dorsal to cells exhibiting SLI (Fig. $1 B$ ), while an intermingling of the two cell types is seen medially (Fig. $1 C)$.

Figure $2 A$ provides a rostrocaudal profile of cells labeled from the DLF, SLI cells, and double-labeled cells. At the level of the inferior olive, SLI cells were found either along the midline in nucleus raphe pallidus (B1) and nucleus raphe obscurus (B2), or at the extreme ventrolateral border of the medulla (nucleus interfascicularis hypoglossi). Cells projecting down the DLF were found in a band between these two serotonergic cell groups, extending from the dorsal accessory nucleus of the inferior olive into the nucleus reticularis pars ventralis or, at more rostral olivary levels, the nucleus reticularis gigantocellularis. An occasional double-labeled cell was seen at the lateral edge of nucleus raphe obscurus or just above the inferior olive.

Approaching the rostral pole of the inferior olive, SLI cells form an unbroken band which extends from the midline to the ventrolateral border of the medulla. At this same level, SLI cells within nucleus raphe obscurus become less numerous. The effect is a gradual disappear- ance of nucleus raphe obscurus and simultaneous fusion of the medial and lateral groups in successively more rostral sections. Cells labeled from the DLF appear with increasing frequency near the midline and, with the disappearance of the inferior olive, form a horizontally oriented band extending from the midline laterally over the pyramids.

The most extensive group of cells labeled from the DLF occurs at the level of nucleus raphe magnus and the facial nucleus. At this level these cells form an arched band which extends from the midline, up over the pyramids to the medial edge of the facial nucleus. On the midline, cells are found within the nucleus raphe magnus where their ventralmost extent is the nucleus raphe pallidus. More laterally, however, the cells follow an arched line extending from the pyramids ventrally, well into the nucleus reticularis gigantocellularis. This entire band of DLF projecting cells has been termed the nucleus raphe alatus (Watkins and Mayer, 1982). It appears to form a functional unit (Zorman et al., 1981). At this same level, SLI cells were found in the nucleus raphe magnus medially, intermingled with DLF projecting cells. More laterally, SLI cells occupy a generally more ventral position, lying between the cells of nucleus raphe alatus and the pyramids. A few SLI cells were seen within the pyramids or on their ventral border. An occasional double-labeled cell was seen either medially or at the dorsoventral border between the lateral parts of B3 and nucleus raphe alatus.

At the level including the genu of the VIIth nerve and the trapezoid body, there is an intermingling of SLI and retrogradely labeled cells within the rostral nucleus raphe magnus. Retrogradely labeled cells tend to be concentrated near the midline, whereas serotonergic cells extend laterally over the trapezoid body. In summary, virtually all cells retrogradely labeled from the DLF were nonserotonergic.

Results using injections of HRP solutions. Large liquid injections of an HRP solution $(20 \% \mathrm{w} / \mathrm{v}, 10 \mu \mathrm{l})$ into the lumbar cord resulted in extensive double labeling of all of the 5 -HT cell groups of the lower medulla. As shown in Figure $2 B$, extensive retrograde labeling of the reticular core was achieved. In a typical section at the level of the facial nucleus, $75 \%$ of the serotonergic neurons were double labeled. Thus, the results of Bowker et al. (1981a) have been confirmed, and we have demonstrated the validity of the double-staining procedure in our laboratory.

Combining lumbar HRP injections with unilateral or bilateral cervical lesions of the DLF provided two important results. First, DLF lesions failed to eliminate retrograde labeling in histochemically identified serotonergic neurons in the ventral medulla. As seen in Figure 3, double-labeled cells are seen both medially in nucleus raphe magnus (Fig. $3 A$ ) and laterally (Fig. $3 B$ ). Thus axons from these neurons can reach the spinal cord by routes other than the DLF. Second, we found a considerable overlap in the distribution of DLF projecting and non-DLF projecting bulbospinal neurons. This heterogeneity is further complicated by the extensive mixture of neurochemically distinct cell types. These findings are illustrated in Figure 4.

Internal controls. The validity of these results is, of 

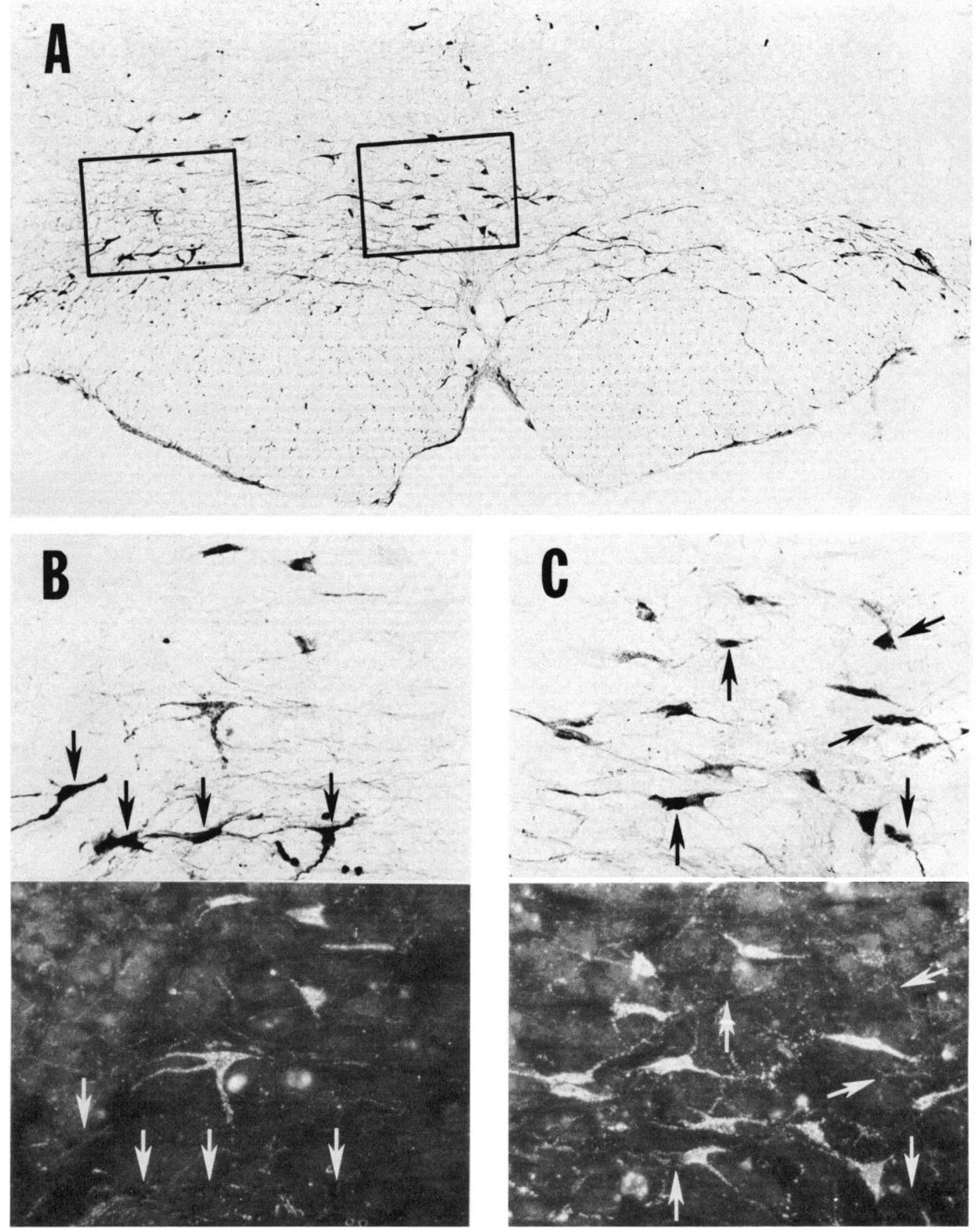

Figure 1. A, Photomicrograph of the rat ventral medulla at the level of the nucleus raphe magnus illustrating the pattern of staining resulting from a unilateral placement of HRP in the left cervical DLF combined with 5-HT immunohistochemistry. A large group of DLF projecting cells can clearly be seen lying dorsal to 5-HT cells on the left. This section is taken from the case drawn in Figure $2 A . B$, Lateral portion of Figure $1 A$. In the brightfield view (upper), the granular HRP reaction product can be seen in DLF projecting cells, which lie dorsal to the darker 5-HT cells (black arrows). In the darkfield view (lower), the retrograde HRP reaction product appears as white grains. Note the lack of grains in the 5 -HT cells (white arrows). $C$, Near the midline, there is an extensive intermingling of DLF projecting and 5-HT cells. Again, the 5-HT cells seen in the upper brightfield view (black arrows) disappear when viewed under darkfield conditions (white arrows). 


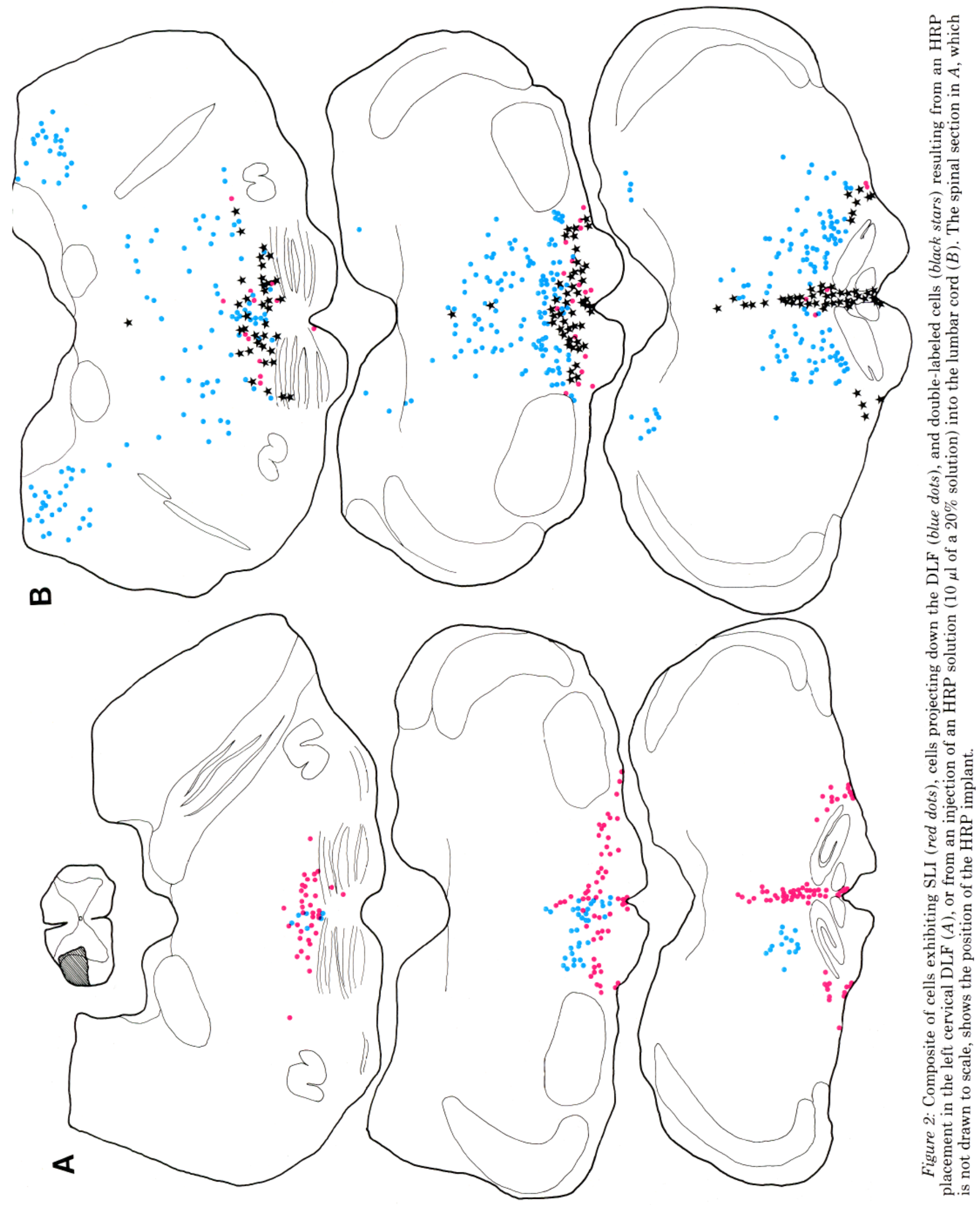



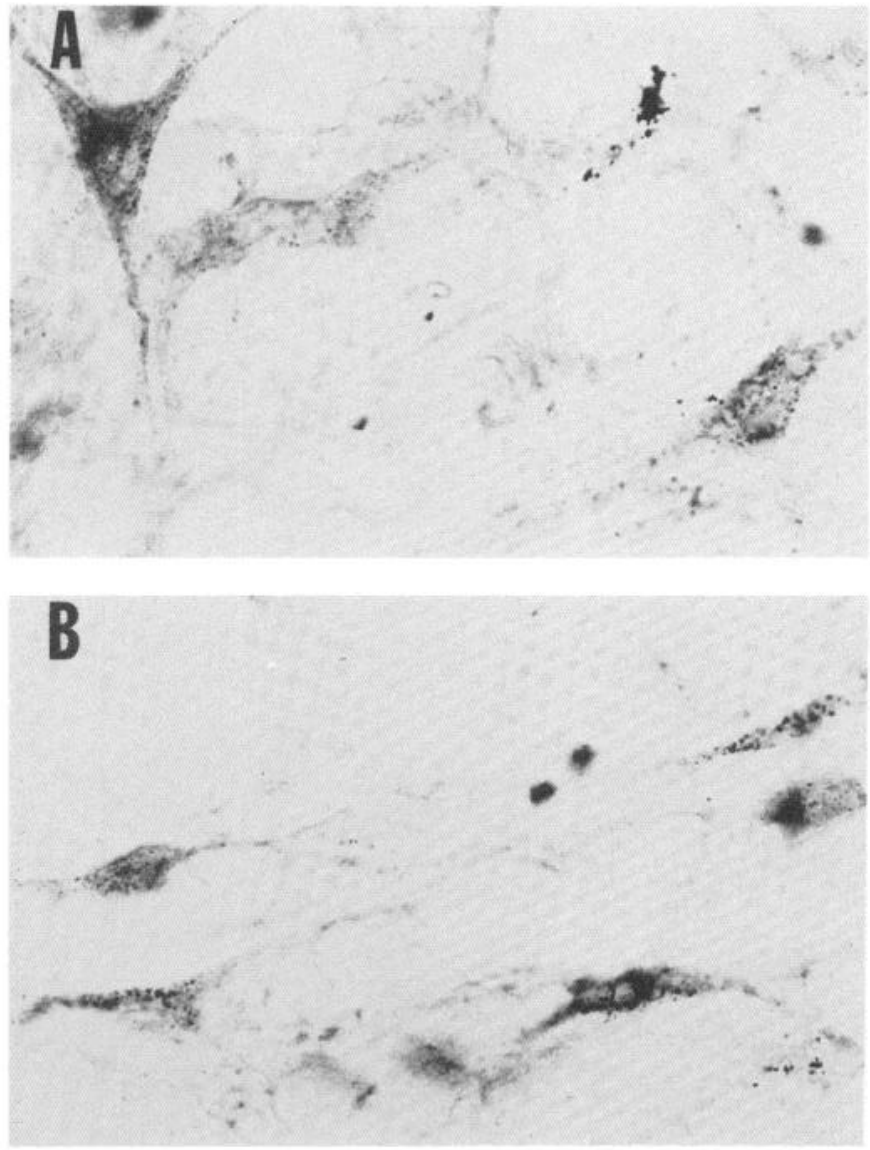

Figure 3. Serotonin cells retrogradely labeled from the lumbar cord in an animal with bilateral lesions of the cervical DLF. At the level of the facial nucleus, double-labeled cells are seen both medially $(A)$ and laterally $(B)$.

course, dependent on the specificity of the SLI staining and the completeness of the retrograde staining from the DLF. The distribution of SLI cells corresponded to the pattern of histofluorescent cells described by Dahlström and Fuxe (1964) and with the previous description of SLI cells by Steinbusch (1981). The staining intensity was reduced in rats not pretreated with L-tryptophan and pargyline. Additionally, the substitution of rabbit primary antisera directed against other antigens (e.g., $\beta$ endorphin) yielded a completely different pattern of staining. These results strongly suggest the staining is specific for 5-HT-containing neurons.

The possibility that 5-HT immunoreactivity obscured weak retrograde staining, or that the $\mathrm{CoCl}_{2}$-DAB method was insensitive and failed to detect a significant number of retrogradely labeled cells, was examined by staining alternate sections with BDHC, a more sensitive HRP method, and comparing the distributions of cells. The $\mathrm{DAB}-\mathrm{CoCl}_{2}$ retrograde staining did provide variable results. Some double-labeled material was nearly devoid of retrograde staining, whereas other cases provided retrograde labeling equivalent to that seen with BDHC. The data presented are from these latter cases.

In summary, we find that cells at the origin of the cervical DLF in the ventral medulla are predominantly non-serotonergic. This result has been confirmed by two approaches: by the absence of a significant number of double-labeled cells after discrete retrograde labeling from the DLF, and by the persistence of double-labeled 5 -HT cells after surgical lesions of one or both DLFs. Furthermore, DLF projecting cells, serotonergic nonDLF projecting cells, and non-serotonergic, non-DLF projecting cells were found to intermingle extensively in the nucleus raphe magnus indicating an extensive heterogeneity within this area.

\section{Discussion}

Our results provide the first direct evidence that the vast majority of cells within nucleus raphe magnus and nucleus reticularis gigantocellularis which descend via the DLF are non-serotonergic. The existence of this large non-serotonergic bulbospinal pathway within the DLF is supported by previous behavioral, physiological, and anatomical results.

Functional activity in this raphe-spinal pathway a measured by behavioral and physiological methods suggests a non-serotonergic component. Behaviorally, potent analgesia can be elicited in both the cat (Oliveras et al., 1975) and the rat (Zorman et al., 1981) by electrical stimulation of the ventral medulla. In both cases the analgesia can be blocked by naloxone. In the rat this blockade also results if the naloxone is restricted to the spinal cord, indicating that a spinal opioid synapse mediates the analgesia. Therefore, if analgesia resulting from stimulation of the ventral medulla results solely from descending serotonergic terminals activating intrinsic spinal opioid interneurons, then analgesia elicited by intrathecal 5-HT should be naloxone reversible. It is not (Yaksh and Wilson, 1979). Two other forms of analgesia are mediated by spinal opiates (Watkins and Mayer, 1982): analgesia resulting from brief acute shock applied to the forelimbs, and a classically conditioned form of analgesia which results from exposure to a non-electrified grid following three daily periods of shock. Both forms of analgesia are blocked by lesions of the ventral medulla or the DLF, and by intrathecal naloxone. While analgesia induced by acute shock is attenuated by spinal 5 -HT depletion, classically conditioned analgesia is not (Watkins et al., 1984). At the physiological level, the increased activity of certain raphe-spinal cells in response to noxious peripheral stimulation and to systemic morphine (Anderson et al., 1977) is strongly indicative of their participation in bulbospinal inhibition. However, within the cat nucleus raphe magnus the vast majority of cells exhibit conduction velocities much higher than those characteristic of serotonergic neurons (West and Wolstencroft, 1977). This paucity of slowly conducting cells is seen even when the sample population is restricted to DLF projecting cells which respond to noxious stimuli (Anderson et al., 1977). In addition, the inhibition of second-order nociceptive neurons by medullary raphe stimulation is only minimally affected by serotonin antagonists (Griersmith et al., 1981; Yezierski et al., 1982). Thus, behavioral and physiological evidence indicate the importance of non-serotonergic pathways within the DLF in the production of analgesia. 

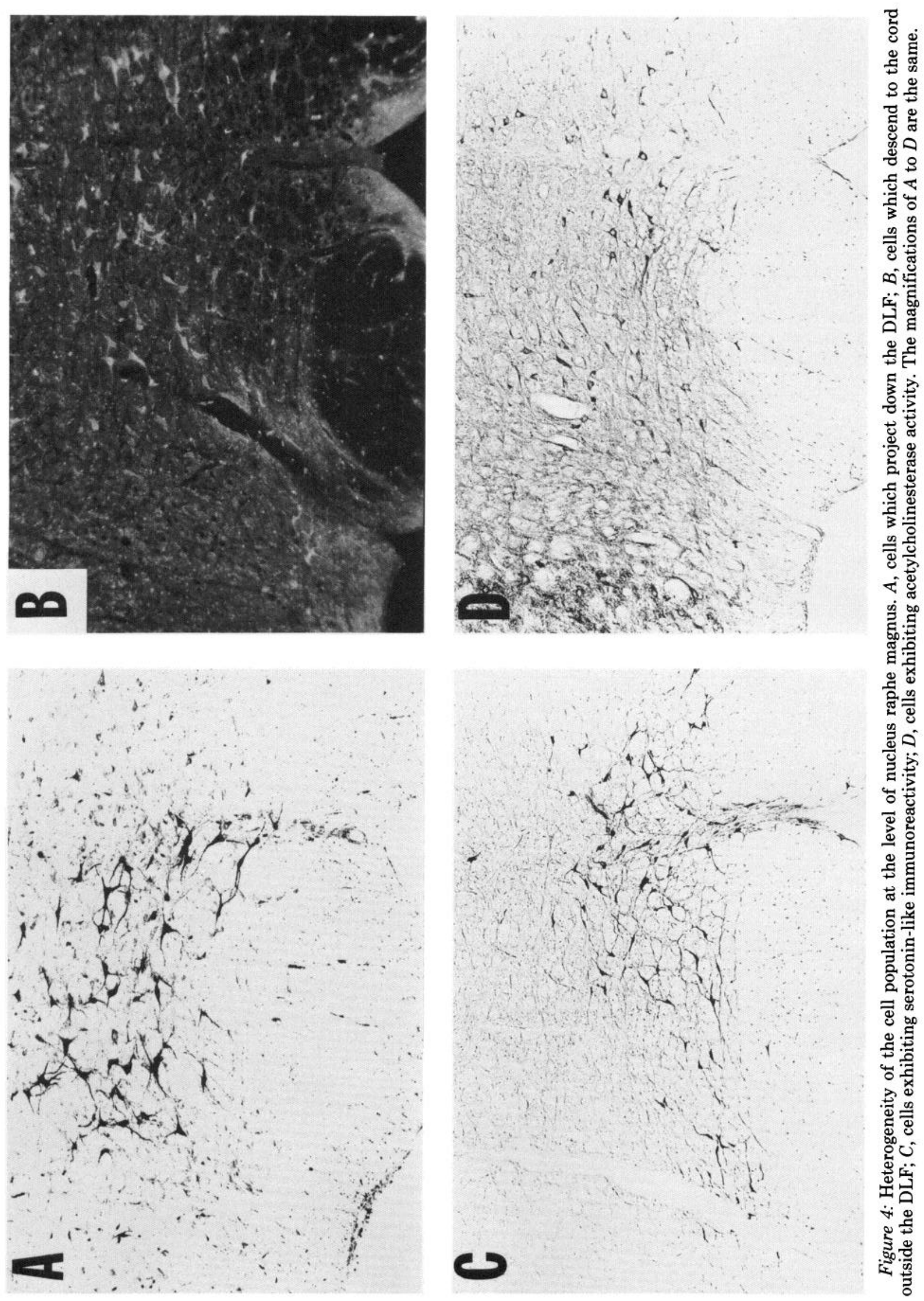
Other anatomical evidence is consistent with our conclusion that the ventral medulla-DLF pathway is nonserotonergic. Injections of tritiated amino acids into the cat nucleus raphe magnus reveal a heavy projection which descends via the DLF to terminate in the dorsal horn-specifically in the marginal zone, substantia gelatinosa, and laminae V (Basbaum et al., 1976; Holstege and Kuypers, 1982). Several facts suggest that this pathway is predominantly non-serotonergic. First, Wiklund et al. (1981) have found that serotonergic neurons comprise only a minor portion of the cells in the nucleus raphe magnus. Second, Holstege and Kuypers (1982) have demonstrated the same DLF projection and spinal terminal distribution following injections into lateral areas which are devoid of serotonergic cells. Third, the pattern of serotonergic terminals seen in the dorsal horn does not match the laminar pattern of terminals origi- nating in nucleus raphe magnus. Whereas serotonergic staining in the superficial layer of the dorsal horn is heavy, the remainder of the dorsal horn shows a more uniform fiber density (Ruda et al., 1982). In addition, Nishikawa et al. (1982) have provided direct evidence that serotonergic terminals are not found exclusively on nociceptive second-order neurons, but are also found in abundance on lamina IV cells which project via the dorsal columns to the dorsal column nuclei. In total these facts suggest that the bulbospinal pathway originating in nucleus raphe magnus described by Basbaum et al. (1976) and by Holstege and Kuypers (1982) is predominantly non-serotonergic.

In addition to our main conclusion of a non-serotonergic predominance in the bulbospinal-DLF pathway, our data imply that only a small fraction of 5 -HTcontaining cells in the ventral medulla descend to the
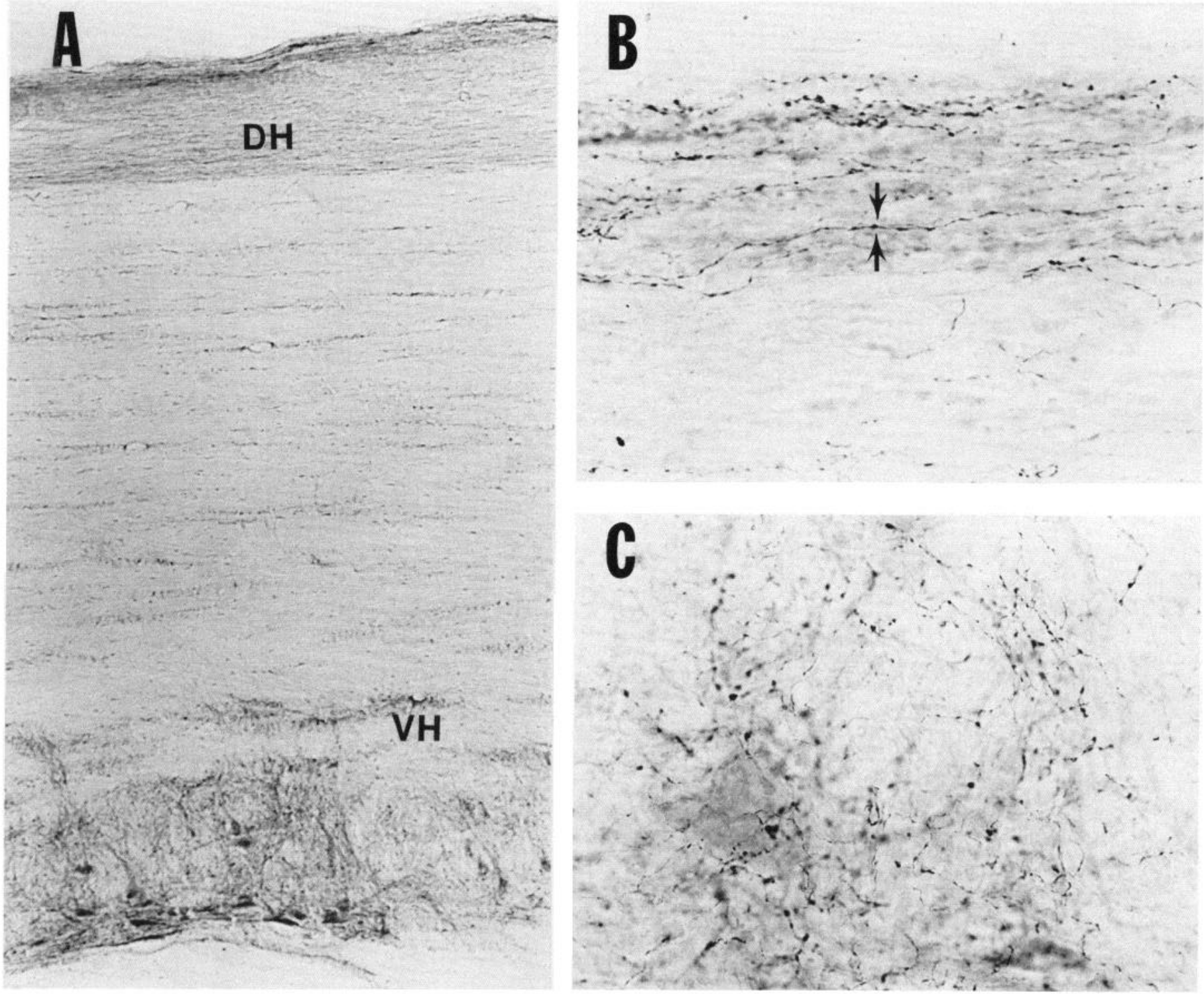

Figure 5. Sagittal view of the rat cervical spinal cord stained for SLI. Whereas the ventral horn $(C)$ exhibits a random 5 -HT fiber pattern, 5-HT fibers in the dorsal cord $(B)$ are arranged in a rostrocaudal direction. Long single axons can be followed within a section for considerable distances (arrows), suggesting the possibility that some serotonergic fibers descend to the cord exclusively within the dorsal horn. $V H$, ventral horn; $D H$, dorsal horn; the intervening white matter is the lateral funiculus. 
cord via the DLF. Both Dahlström and Fuxe (1965) and Steinbusch (1981) have noted 5-HT-containing fibers in the spinal white matter, primarily in ventral areas but also within the DLF. Since we have not attempted a quantitative approach, it is unclear whether the small number of serotonin-containing cells labeled from the DLF is sufficient to account for these observations. However, several possibilities emerge for alternate routes for descending serotonergic fibers. First, Dahlström and Fuxe (1965) show 5-HT-containing fibers entering the dorsal horn from the ventral, intermediate and dorsal aspects of the lateral funiculus, suggesting a diffuse route of descent. Second, SLI fibers have been described within the dorsal columns (Hancock, 1982). As yet the origin of these fibers is unknown. A third possibility emerges from a close examination of the arrangement of 5-HT fibers in the spinal cord. When viewed in the sagittal plane, serotonergic fiber patterns differ greatly between the dorsal and ventral horn (Fig. 5). Ventral horn fibers are randomly oriented (Fig. $5 \mathrm{C}$ ), and fibers can be seen entering and leaving the gray matter. On the other hand, fibers in the dorsal horn adhere to a distinct rostrocaudal orientation. Single fibers can be followed for considerable distances (Fig. $5 B$ ) and are rarely seen entering or leaving the gray matter. This strongly suggests that some serotonergic fibers descend entirely within the confines of the dorsal horn, influencing large segments of spinal cord by virtue of numerous boutons of passage. The fact that cells within the ventral medulla innervate multiple cord levels (Huisman et al., 1981) is consistent with this hypothesis.

Serotonergic fibers lying outside the DLF do appear to have a functional role in the production of analgesia. Whilc the argument has been made here that behavioral, physiological, and anatomical evidence indicate that the notion of a bulbospinal serotonergic system acting as a final common pathway for all forms of analgesia is clearly incorrect, there is evidence that spinal 5-HT depletion does attenuate some forms of endogenously mediated analgesia (Watkins et al., 1983). Similarly, descending noradrenergic pathways which are implicated in analgesia (Kuraishi et al., 1979; Reddy and Yaksh, 1980) also lie outside the DLF (Kaufman et al., 1983). It is important to note that, although DLF lesions attenuate analgesia elicited by systemic morphine and manipulations of the PAG, with the exception of electrophysiological paradigms the effects of DLF lesions on analgesia elicited from the ventral medulla are as yel untested.

Behavioral evidence indicates that analgesia may result from simultaneous activation of pathways inside and outside the DLF. As previously mentioned the acute and conditioned forms of footshock-induced analgesia are similar in that they are both blocked by DLF lesions or by intrathecal naloxone, but only the acute form is also attenuated by spinal 5-HT depletion. Since our data indicate that this serotonergic pathway lies outside the DLF, coactivation of two pathways is necessary for this form of analgesia. Furthermore, since the conditioned analgesia is unaffected by spinal 5-HT depletion, elements within the DLF other than those involved in the acute form of the analgesia must be involved-elements which do not require simultaneous serotonergic activation to exert their inhibitory action at the spinal level.
In conclusion, the emerging picture of bulbospinal pathways which inhibit the ascending flow of information about noxious stimuli is complex. There is evidence for multiple pathways which vary in their neurochemical nature and in their route of descent. Analgesia may result from the activation of one or a combination of these pathways. We have shown that the origins of these pathways often do not form discrete nuclei but are comprised of diffuse groups of cells which often intermingle. In light of these facts, new strategies will be required to dissect out the contributions these various cell groups make to the production of analgesia.

\section{References}

Akaike, A., T. Shibata, M. Satoh, and H. Takagi (1978) Analgesia induced by microinjection of morphine into, and electrical stimulation of, the nucleus reticularis paragigantocellularis of rat medulla oblongata. Neuropharmacology 17: 775778.

Anderson, S. D., A. I. Basbaum, and H. L. Fields (1977) Response of medullary raphe neurons to peripheral stimulation and to systemic opiates. Brain Res. 123: 363-368.

Basbaum, A. I., and H. L. Fields (1979) The origin of descending pathways in the dorsolateral funiculus of the spinal cord of the cat and rat: Further studies on the anatomy of pain modulation. J. Comp. Neurol. 187: 513-532.

Basbaum, A. I., C. H. Clanton, and H. L. Fields (1976) Opiate and stimulus-produced analgesia: Functional anatomy of a medullospinal pathway. Proc. Natl. Acad. Sci. U. S. A. 73: 4685-4688.

Basbaum, A. I., N. J. E. Marley, J. O'Keefe, and C. H. Clanton (1977) Reversal of morphine and stimulus-produced analgesia by subtotal spinal cord lesions. Pain 3: 43-56.

Belcher, G., R. W. Ryall, and R. Schaffner (1978) The differential effects of 5-hydroxytryptamine, noradrenalin and raphe stimulation on nociceptive and non-nociceptive dorsal horn interneurons in the cat. Brain Res. 151: 307-321.

Bourgoin, S., J. L. Oliveras, J. Bruxell, M. Hamon, and J. M. Besson (1980) Electrical stimulation of the nucleus raphe magnus in the rat. Effects of 5-HT metabolism in the spinal cord. Brain Res. 194: 377-389.

Bowker, R. M., H. W. M. Steinbusch, and J. D. Coulter (1981a) Serotonergic and peptidergic projections to the spinal cord demonstrated by a combined retrograde HRP histochemical and immunocytochemical staining method. Brain Res. 211: 412-417.

Bowker, R. M., K. N. Westlund, and J. D. Coulter (1981b) Origins of serotonergic projections to the spinal cord in rat: An immunocytochemical-retrograde transport study. Brain Res. 226: 187-199.

Dahlström, A., and K. Fuxe (1964) Evidence for the existence of monoamine-containing neurons in the central nervous system. I. Demonstration of monoamines in the cell bodies of brain stem neurons. Acta Physiol. Scand. 62 (Suppl. 232): $1-55$.

Dahlström, A., and K. Fuxe (1965) Evidence for the existence of monoamine-containing neurons in the central nervous system. II. Experimentally induced changes in the intraneuronal amine levels of bulbospinal neuron systems. Acta Physiol. Scand. 64 (Suppl. 247): 1-36.

Dickenson, A. J., J. L. Oliveras, and J. M. Besson (1979) Role of the nucleus raphe magnus in opiate analgesia as studied by the microinjection technique in the rat. Brain Res. 170: 95-111.

Engberg, I., A. Lundberg, and R. W. Ryall (1968) Is the tonic decerebrate inhibition of reflex paths mediated by monoaminergic pathways? Acta Physiol. Scand. 72: 123-133.

Fields, H. L., A. I. Basbaum, C. H. Clanton, and D. A. Anderson 
(1977) Nucleus raphe magnus inhibition of spinal cord dorsal horn neurons. Brain Res. 126: 441-453.

Griersmith, B. T., A. W. Duggan, and R. A. North (1981) Methysergide and supraspinal inhibition of the spinal transmission of nociceptive information in the anesthetized cat. Brain Res. 204: 147-158.

Griffin, G., L. R. Watkins, and D. J. Mayer (1979) HRP pellets and slow release gels: Two new techniques for greater localization and sensitivity. Brain Res. 168: 595-601.

Hancock, M. B. (1982) A serotonin-immunoreactive fiber system in the dorsal columns of the spinal cord. Neurosci. Lett. 31: $247-252$.

Headley, P. M., A. W. Duggan, and B. T. Griersmith (1978) Selective reduction by noradrenaline and 5-hydroxytryptamine of nociceptive responses of cat dorsal horn neurons. Brain Res. 145: 185-189.

Holmqvist, B., and A. Lundberg (1959) On the organization of the supraspinal inhibitory control of interneurons of various spinal reflex arcs. Arch. Ital. Biol. 97: 340-356.

Holstege, G., and H. G. J. M. Kuypers (1982) The anatomy of brain stem pathways to the spinal cord in cat. A labeled amino acid tracing study. Prog. Brain Res. 57: 145-175.

Husiman, A. M., H. G. J. M. Kuypers, and C. A. Verburgh (1981) Quantitative differences in collateralization of the descending spinal pathways from red nucleus and other brain stem cell groups in rat as demonstrated with multiple fluorescent retrograde tracer technique. Brain Res. 209: 271286.

Johannessen, J. N., L. R. Watkins, S. M. Carlton, and D. J. Mayer (1982) Failure of spinal cord serotonin depletion to alter analgesia elicited from the periaqueductal gray. Brain Res. 237: 373-386.

Jordan, L. M., D. R. Kenshalo, Jr., R. F. Martin, L. H. Haber, and W. D. Willis (1978) Depression of primate spinothalamic tract neurons by iontophoretic application of 5-hydroxytryptamine. Pain 5: 135-142.

Kaufman, E. F. S., R. M. Fay, J. N. Johannessen, L. R. Watkins, and D. J. Mayer (1983) Encephalospinal analgesia systems: Noradrenergic component does not descend in the dorsolateral funiculus (DLF). Soc. Neurosci. Abstr. 9: 000.

Kuraishi, Y., Y. Harada, and H. Takagi (1979) Noradrenaline regulation of pain-transmission in the spinal cord mediated by alpha-adrenoceptors. Brain Res. 174: 333-336.

Mesulam, M. M. (1976) The blue-reaction product in horseradish peroxidase neurohistochemistry: Incubation parameters and visibility. J. Histochem. Cytochem. 24: 1273-1280.

Murfin, R., G. Bennett, and D. J. Mayer (1976) The effect of dorsolateral spinal cord lesions on analgesia from morphine microinjected into the periaqueductal gray matter. Soc. Neurosci. Abstr. 2: 946.

Nishikawa, N., M. A. Ruda, G. J. Bennet, and R. Dubner (1982) Serotonergic innervation of dorsal column post synaptic spinomedullary neurons in the cat and monkey. Soc. Neurosci. Abstr. 8: 93.

Oliveras, J. L., F. Redjemi, G. Guilbaud, and J. M. Besson (1975) Analgesia induced by electrical stimulation of the inferior centralis nucleus of the raphe in the cat. Pain 1:139145.

Proudfit, H. K., and T. L. Yaksh (1980) Alterations in nociceptive threshold and morphine-induced analgesia following the selective depletion of spinal cord monoamines. Soc. Neurosci. Abstr. 6: 143 .

Randic, M., and H. H. Yu (1976) Effects of 5-hydroxytryptamine and bradykinin in cat dorsal horn neurons activated by noxious stimuli. Brain Res. 111: 197-203.

Reddy, S. V. R., and T. L. Yaksh (1980) Spinal noradrenergic terminal system mediates antinociception. Brain Res. 189: $391-401$
Ruda, M. A., and S. Gobel (1980) Ultrastructural characterization of axonal endings in the substantia gelatinosa which take up $\left[{ }^{3} \mathrm{H}\right]$-serotonin. Brain Res. 184: 57-83.

Ruda, M. A., J. Coffield, and H. M. W. Steinbusch (1982) Immunocytochemical analysis of serotonergic axons in laminae I and II of the lumbar spinal cord of the cat. J. Neurosci. 2: $1660-1671$.

Rydenhag, B., and S. Andersson (1981) Effect of DLF lesions at different spinal levels on morphine induced analgesia. Brain Res. 212: 239-242.

Satoh, M., A. Akaike, T. Nakazawa, and H. Takagi (1980) Evidence for involvement of separate mechanisms in the production of analgesia by electrical stimulation of the nucleus reticularis paragigantocellularis and nucleus raphe magnus in the rat. Brain Res. 194: 525-529.

Shiomi, H., H. Murakami, and H. Takagi (1978) Morphine analgesia and bulbospinal serotonergic system: Increase in concentration of 5-hydroxyindoleacetic acid in the rat spinal cord with analgesics. Eur. J. Pharmacol. 52: 335-344.

Soja, P. J., and J. G. Sinclair (1980) Evidence against a serotonin involvement in the tonic descending inhibition of nociceptor-driven neurons in the cat spinal cord. Brain Res. 199: 225-230.

Steinbusch, H. W. M. (1981) Distribution of serotonin-immunoreactivity in the central nervous system of the rat-cell bodies and terminals. Neuroscience $6: 557-618$.

Vogt, M. (1973) 'Ihe effect of lowering the 5-hydroxytryptamine content of the rat spinal cord on analgesia produced by morphine. J. Physiol. (Lond.) 236: 483-498.

Wang, J. K. (1977) Antinociceptive effect of intrathecally administered serotonin. Anesthesiology 47: 269-271.

Watkins, L. R., and D. J. Mayer (1982) Organization of endogenous opiate and non-opiate pain control systems. Science 216: 1185-1192.

Watkins, L. R., G. Griffin, G. R. Leichnetz, and D. J. Mayer (1980) The somatotopic organization of the nucleus raphe magnus and surrounding brain stem structures as revealed by HRP slow-release gels. Brain Res. 181:1-15.

Watkins, L. R., J. N. Johannessen, I. B. Kinscheck, and D. J. Mayer (1984) The neurochemical basis of footshock analgesia: The role of spinal cord serotonin and norepinephrine. Brain Res. 290: 107-117.

West, D. C., and J. H. Wolstencroft (1977) Location and conduction velocity of raphe spinal neurons in nucleus raphe magnus and raphe pallidus in the cat. Neurosci. Lett. 5: 147151.

Wiklund, L., L. Leger, and M. Persson (1981) Monoamine cell distribution in the cat brainstem. A fluorescence histochemical study with quantification of indoleaminergic and locus coeruleus cell groups. J. Comp. Neurol. 203: 613-647.

Willis, W. D., L. H. Haber, and R. F. Martin (1977) Inhibition of spinothalamic tract cells and interneurons by brain stem stimulation in the monkey. J. Neurophysiol. 40: 968-981.

Yaksh, T. L. (1979) Direct evidence that spinal serotonin and noradrenaline terminals mediate the spinal antinociceptive effects of morphine in the periaqueductal gray. Brain Res. 160: $180-185$.

Yaksh, T. L., and P. R. Wilson (1979) Spinal serotonin terminal system mediates antinociception. J. Pharmacol. Exp. Ther. 208: 446-453.

Yezierski, R. P., T. K. Wilcox, and W. D. Willis (1982) The effects of serotonin antagonists on the inhibition of primatc spinothalamic tract cells produced by stimulation in nucleus raphe magnus or periaqueductal gray. J. Pharmacol. Exp. Ther. 220: 266-277.

Zorman, G., I. D. Hentall, J. E. Adams, and H. L. Fields (1981), Naloxone-reversible analgesia produced by microstimulation in the rat medulla. Brain Res. 219: 137-148. 